\title{
The Effectiveness of Information in the Center for Quality and Accreditation at the University of Science and Technology from the Point of View of Faculty Members
}

\author{
Dr..Rawan kheder yousef abu shaqra \\ University of Science and Technology, Faculty of Arts and Sciences, Department of Human Sciences
}

\begin{abstract}
The study aimed at revealing the effectiveness of the training programs in the Center for Quality and Accreditation at the University of Science and Technology from the point of view of the faculty members. To achieve the objectives of the study, the researcher used a questionnaire consisting of 25 paragraphs divided into four areas that measure the effectiveness of training programs in the Quality and Accreditation Center at the University of Science and Technology (2059). The questionnaire was distributed randomly to the study sample of 309 members and members of the faculty. The researcher also used the descriptive approach that fits the nature of the study The results showed that there were statistically significant differences in (0.05) in the total score on the tool due to the sex variable and for the benefit of males and there were significant differences at the level of significance $(0.05)$ attributable to the impact of academic rank and to the rank of assistant professor. For the type of college and for the benefit of scientific colleges. The study made several recommendations he most important of which is the need to encourage all colleges to cooperate with the training centers in universities to reach training programs that are more useful. The need to focus on the involvement of females in a greater proportion in the numbers and implementation, design and implementation of these programs. The need to strengthen the training center at the university with specialized cadres of human resources management, which takes into account the dimensions of the training process, which have emerged as important and direct relationship to the effectiveness of training
\end{abstract}

Keywords: Training Programs, Quality and Accreditation Center

DOI: $10.7176 / \mathrm{JEP} / 10-24-12$

Publication date: August 31st 2019

\section{1- Introduction}

The Higher education is one of the most important elements in the process of comprehensive development, and we do not forget its importance in achieving progress and development in all its intellectual, political, economic, scientific and practical fields. Therefore, it is considered one of the most important means to develop the basic skills and abilities of faculty members in different universities, Higher education is a high investment in all capacities for various human resources to achieve community service and contribute to comprehensive development. Therefore, teaching and continuous training are among the most important goals that must be achieved by universities. Adegbija, 2015))

Comprehensive training and rehabilitation is one of the most important issues and trends that still occupy the decision-makers in the universities from deans, heads of departments, educational policy planners, university departments and heads, focusing on training, human resource development, improving skills and knowledge, diversity of leadership styles and diversity in faculty development programs. Training is an urgent and imperative necessity for institutions of higher education, so that it is one of the most important strategic axes that work on continuous improvement of the performance of individuals and then achieve their competitive advantage. $\mathrm{T}$ is one of the most important types of human investment. (Sarifi, 2009).

Training programs in higher education institutions and specifically universities in achieving their objectives represent a major response to the increasing investment of labor by increasing the levels of current work skills And the development of new skills represented by the generation and development of new ideas, innovative and innovative in the field of work, the training of the role of the largest and the most important, it was necessary to develop training programs effective and diverse to achieve the objectives in addition to the diversity and diversity and diversity Vosha Methods and methods. These programs should be carried out in specialized scientific ways, adapted to the nature of the activity required to be developed and in line with the general objectives of the University and its vision and mission. (Ramadi, 2012).

Therefore, improving the quality of higher education has become one of the most important strategic objectives of all higher education institutions, which includes all the functions of education and its activities, which include study programs, faculty members, which include training and continuous development through training programs provided by the Center for Accreditation and Quality Assurance, , Which tracks the development of education in developed countries, notes its focus and special attention to quality through continuous review, training and continuous development of faculty members and all administrative staff (Hatherm, 2017)

The concept of training: The concept of training is one of the necessary concepts that all educational 
institutions seek to activate in a full and integrated manner in all fields. Therefore, every individual in the institution undergoes training from time to time or from time to time, in order to change the behavior of individuals in the desired and desired direction. To strive to have all the skills, knowledge and abilities that lead them to achieve the desired goal. Therefore, the training in educational institutions carries a kind of privacy by targeting the faculty members. The success of the educational institutions depends on its ability to prepare the human cadres of the appropriate faculty members. This role can be played by the training programs in the center of accreditation and quality assurance in the universities. (Al-Sakarna, 2009).

The training, as mentioned by Kubaisi (2010), is defined as: a set of steps, processes and programs designed to modify behavior in accordance with future requirements. As Morsi (2003) defines it as a stable activity with the skills, experience and attitudes that make it good for doing business.

The researcher notes from the previous definitions that training is the process that aims to increase the faculty members' understanding of skills and knowledge in order to carry out the duty entrusted to him to the fullest extent. It plays a key role in the lives of individuals within educational institutions through many of the goals it seeks to achieve, as mentioned by a group of authors (Baldwin, 2008; Jassim, 2012; Haidar, 2012):

- To fund the institution with the necessary and continuous human resources through the development of human resources and their level to suit the existing requirements. Helping teachers to reduce their supervision process, as employees become self-critical, self-reliant, qualified and well-trained after they are familiar with all their tasks and tasks. , Instilling new work ethics, new behaviors and modern ways of sound thinking, creating a suitable and appropriate job climate and motivation for action.

- Achieving the organization's goals, vision and mission. Increase efficiency, productivity and reduce expenditures, and stabilize production to ensure that they continue to work.

7-2 - The importance of training: It is noted that training in educational institutions or in centers of quality and accreditation in universities aims to raise the training capacity and reach the standards required to achieve a distinct level of performance, and on this basis is considered a vital activity in determining the level of efficiency and effectiveness, It is therefore important to improve the performance of human resources, so that the continuous training of the staff helps to increase the performance of the work entrusted to them, and thus increase the production because of their increased skill, training also helps in the formation of many trends as one of the goals The generalization of the training programs is the formation of a specific direction. It benefits the faculty members themselves, since the individual's assimilation of new knowledge and new functional skills will increase the value of the individual in himself both inside and outside the university, acquiring such skills increases the value of the member within The university itself, which increases the chance of feeling safe for the job, and qualify him to upgrade to higher academic levels. Thereby increasing and improving its physical and social status (sparks, 2000) 7-3 - Center for Academic Development and Quality Assurance at the University of Science and Technology.

The Center for Academic Development was established in 2005/2006, while the Quality Assurance and Accreditation Office was established in 2007/08. As a result of the interaction between these two units, it was decided to integrate them in 2010 . The Center has meant supporting the development, modernization and training plans to achieve the highest quality of education at the University. To develop scientific research processes and to strive to improve the quality and quality of academic education and members of the university by supporting strategies and plans to achieve comprehensive sustainable development and activate these plans in the university environment as a whole by enhancing and developing the patterns of education pursued. Teaching staff, through the participation of them in educational and training workshops, enriching their abilities and laying the foundations for evaluating their performance, in addition to setting clear guidelines that maintain the quality of educational levels for students to ensure the quality of the education they receive, Educational Outputs (Khazer, 2007)

The Center organizes orientation and orientation workshops for faculty members at the beginning of the semester each year, and provides all extension services, including the definition of university laws, the definition of academic procedures (such as the course description, evaluation methods, and the marks system) 2018)

1 - Previous studies: Al - Sudairy (2012) conducted a study aimed at identifying the impact of training programs provided by the Deanship of Skills Development on the teaching performance of faculty members at King Saud University. The study sample consisted of 328 faculty members. High in the faculty members of the training programs provided by the Deanship of Skills Development in the areas of planning for teaching, implementation, evaluation and use of technology, and that all programs are considered to be highly effective from the point of view of the study sample. The study also found a statistically significant effect on the variable number of courses attended by a faculty member to benefit from the training programs offered to him for those who attended two sessions or more. While there was no significant effect of gender variables, years of experience and academic level on the degree of benefit from programs. How many

The University of Science and Technology is one of the world's leading universities in the quality of education, knowledge-making, community leadership and development. Its mission is to provide high-quality educational and professional services, contribute to the provision of knowledge, diffusion, leadership and development of human societies and create scientific environments that promote excellence and creativity through faculty 
development and interest.

\section{2- Problem of study:}

The work in public universities and specifically the University of Science and Technology needs to be more modernized, developed and updated especially after the emergence of modern methods and tools. The study aims at identifying the effectiveness of training programs in the Center for Accreditation and Quality at the University of Science and Technology from the point of view of faculty members. And to find out if there are differences in the responses of faculty members to the effectiveness of training programs at the Center for Accreditation and Quality at the University of Science and Technology, according to the study variables. Hence the study questions: Question 1: What is the effectiveness of training programs in the accreditation center at the University of Science and Technology from the point of view of faculty members?

The second question: Are there statistically significant differences at the level of significance $(0.05 \alpha=)$ between the responses of the members of the study sample from the faculty members of the University of Science and Technology to identify the effectiveness of the teaching programs at the Center for Accreditation and Quality at the University of Science and Technology?

3 - Objectives of the study: The study aimed to identify the effectiveness of training programs in the Center for Accreditation and Quality at the University of Science and Technology from the point of view of faculty members. It also aimed to detect whether there were statistically significant differences at the level of $(0.05 \alpha=)$ between the responses of the sample members of the faculty of the University of Science and Technology to identify the effectiveness of the training programs.

4 - The importance of the study: The importance of the study is reflected in the importance of its subject and effectiveness, but it highlights the subject of very important in practical terms, since it addresses the issue of administrative basic depth in the development and development of human cadres through training and training courses, but in practice also show the importance of research from While demonstrating the importance of training in educational institutions and specifically the University of Science and Technology, which is considered one of the basic sources of qualified human resources necessary for the labor market, and in terms of the results of this study can show the shortcomings of the training in the training programs Provided to faculty members. And avoid them and circulate their results to other universities in order to activate training in them.

5 - Study terms: Effectiveness: The extent to which the independent variable affects the effect or improvement of dependent variables. (Abuktouh, 2013). The researcher defines the procedure: What has been measured through the degree given by the respondent to paragraphs to determine the effectiveness of the training programs.

Training programs: These programs are received by employees of the educational institution from technicians, administrators and faculty members during the service to activate them and provide them with everything new in their field of work. Where it aims to improve and improve the level of performance. These programs differ in terms of duration and objectives, and the quality of experiences presented to them (Sabri, 2002). Agaraya: is the activity carried out by the Center for Quality and Accreditation at the University of Science and Technology by giving them training programs for faculty members in the university in order to improve their performance and raise their efficiency.

6 - Limitations of the study and its determinants:

- Time limits: applied during 2018/2019

- Spatial boundaries: The study was applied at the University of Science and Technology.

- Human boundaries: The research was limited to faculty members only.

9. Methodology and procedures of the study:

The study method: To achieve the objectives of the study, the researcher used the analytical descriptive approach, which is the most appropriate for such a study. The questionnaire was used as a means of collecting data for the study and analysis in order to reach the results that help in interpretation and answer the study questions.

9-2-Community and sample of the study: The society of the study is a faculty member of the University of Science and Technology in Irbid Governorate during the academic year 2018/2019 and the number of (2059) members and a member of the faculty. This study was applied to a randomly selected sample of the study population consisting of (320) members and members of the teaching staff at the university. All the questionnaires were distributed to them, all of which were subject to analysis and coding, representing $15.5 \%$ of the society. The study sample was distributed according to variables as shown in the following table(1): 
Table (1) Distribution of the sample of the study by sex, faculty and academic rank

\begin{tabular}{|l|l|l|l|}
\hline variables & Categories & Frequency & ratio \\
\hline \multirow{3}{*}{ Gender } & Male & 207 & $64.7 \%$ \\
\cline { 2 - 4 } & Female & 113 & $35.3 \%$ \\
\hline \multirow{3}{*}{ Acadege } & Humanities & 92 & $28.8 \%$ \\
\cline { 2 - 4 } & Scientific and Applied Sciences & 228 & $71.2 \%$ \\
\cline { 2 - 4 } & Professor & 18 & $5.6 \%$ \\
\cline { 2 - 4 } & Associate Professor & 114 & $35.6 \%$ \\
\cline { 2 - 4 } & Assistant Professor & 188 & $58.8 \%$ \\
\hline Total & 320 & 100 \\
\hline
\end{tabular}

The researcher developed a questionnaire to identify the effectiveness of the training programs at the Center for Accreditation and Quality Assurance at the University of Science and Technology. From the point of view of the faculty members, and taking the views of arbitrators and specialists in this area. The questionnaire was used as a tool for study in its final form. The tool consisted of (25) paragraphs in addition to the basic demographic variables of the research divided into four main areas distributed as follows:

1. The field of the training method consists of (6) paragraphs. The field of evaluation training consists of (6) paragraphs.

2. The field of identification of training needs consists of (5) paragraphs. The field of training content consists of (8) paragraphs.

The five-level Likert scale has been used. Five levels have been identified as follows: (5) large (4), medium (3), weak (2), very weak (1) (5) high grade, and grade (1) is low.

9-3 - The validity of the study tool: To verify the signs of honesty was presented to a group of arbitrators to ascertain the validity of the truth after the design of the questionnaire in the initial image of the (12) arbitrators with expertise and experience who hold a doctorate degree in Jordanian universities in the educational administration, The arbitrators were asked to judge the quality of the content of the paragraphs, to express an opinion on the language and integrity of the paragraph, the appropriateness of the paragraph to the field under which it was included, as well as any other observations they may deem appropriate to be amended, added or deleted. Based on the agreement As arbitrators as a criterion for judging the validity of the phrase. To verify the validity of the building, the researcher used the questionnaire and applied it to a sample of the study community consisting of (20) members of the teaching staff in order to identify the correctness of the internal consistency of the tool and the contribution of its component parts in order to reveal the effectiveness of the training programs in the accreditation center The quality of the University of Science and Technology from the point of view of faculty members, by calculating Pearson correlation coefficient between the paragraphs and the total tool of the study and the fields followed. Table (2) shows the correlation coefficients analysis of the fields of the study instrument.

9.4. Stability of the Study Instrument: To ascertain the stability of the study instrument, the stability coefficient was calculated in the internal consistency method, according to the Cronbach-Alpha equation, which measures the consistency of the responses of the sample to all the paragraphs in the questionnaire. The value of the coefficient of stability for the field of the training method $(0.90)$ and the value of the stability coefficient on the field of training evaluation (0.76) (0.79), and the value of the stability coefficient on the field of training content $(0.90)$. These values are acceptable for study purposes, which is high in the light of the previous studies.

9-6- Study variables: Independent variables:

- Sex has two categories (male, female).

- College and has two categories (human sciences, scientific and applied).

- Academic level with three levels (Assistant Professor, Associate Professor, Professor).

Intermediate variables: The effectiveness of training programs in the Center for Quality and Accreditation at the University of Science and Technology from the point of view of faculty members.

Statistical processing: The following statistical methods were used to process the data statistically:

1. In order to answer the first question, arithmetical averages, standard deviations and levels were used.

2. In order to answer the second question, the mean and standard deviations were calculated. Three-Way ANOVA was used without interaction for the study domains, sex, kidney, and academic variables.

3. The Cronbach-Alpha equation was used to find the coefficient of consistency of the internal consistency and Pearson correlation coefficient to find the internal truth coefficient of the study instrument.

10- Results

1- Results related to the answer to the first question: How effective training programs in the Center for Accreditation and Quality Assurance at the University of Science and Technology from the perspective of faculty members?

In order to answer this question, the arithmetical averages, standard deviations, estimation and grades were extracted to the degree of effectiveness of the training programs at the Center for Accreditation and Quality 
Assurance at the University of Science and Technology from the point of view of faculty members in general and for each field of study. Table (2) illustrates this:

Table (2): Mathematical Meanings and Standard Deviations of Tool Fields for the Effectiveness of Training Programs at the Center for Accreditation and Quality Assurance at the University of Science and Technology from the point of view of faculty members.

\begin{tabular}{|l|c|c|l|l|}
\hline The field & Mean & standard deviation & Degree of assessment & Ranking \\
\hline Training method & $\mathbf{3 . 3 3}$ & $\mathbf{0 . 9 9}$ & big & 1 \\
\hline Training Calendar & $\mathbf{3 . 1 4}$ & $\mathbf{0 . 7 0}$ & Medium & 2 \\
\hline Identification of training needs & $\mathbf{3 . 1 6}$ & $\mathbf{0 . 7 3}$ & Medium & 3 \\
\hline Training content & $\mathbf{3 . 0 7}$ & $\mathbf{0 . 8 9}$ & Medium & 4 \\
\hline Total arithmetic mean & $\mathbf{3 . 2 0}$ & $\mathbf{0 . 6 4}$ & Medium & \\
\hline
\end{tabular}

Table (2) shows that the areas of effectiveness of the training programs at the Center for Accreditation and Quality Assurance at the University of Science and Technology from the point of view of the faculty members were medium. This is due to the close response of the study sample to the survey questionnaire which measures the effectiveness of the training programs in the accreditation center The results of this study were agreed with the study of Zein (2017) and the study of shahrouz fariad (2012), while the results of this study differed with the study of al-Sudairy (2012), which showed the effectiveness of the training programs. (3.99), with a standard deviation $(0.99)$ and a high level of evaluation. The second area was the field of training needs assessment, where the mean (3.16), the standard deviation (0.73) and the level of assessment (3.74), with a standard deviation of (0.70) and with an average grade of evaluation. Finally, the field of training content reached (3.07) with a standard deviation (0.89) and an average grade of assessment, And the total arithmetic mean was I hope the study tool (3.20) and standard deviation (0.64) and the level of medium evaluation.

In order to identify the paragraphs according to the fields under them, the mathematical averages and standard deviations of the effectiveness of training programs in the Center for Accreditation and Quality Assurance at the University of Science and Technology were calculated from the point of view of the faculty members for each paragraph. A presentation of results by field and table (4) shows that:

Table (3) Mathematical averages and standard deviations of the fields of effectiveness of training programs in the Center for Accreditation and Quality Assurance at the University of Science and Technology from the point of view of faculty members descending order by arithmetic averages

\begin{tabular}{|c|l|l|l|l|}
\hline Number & Field & Mean & $\begin{array}{l}\text { Standard } \\
\text { Deviation }\end{array}$ & Ranking \\
\hline 1. & $\begin{array}{l}\text { The trainer uses the training method that is appropriate to the } \\
\text { purpose of the course. }\end{array}$ & 3.65 & 1.19 & 1 \\
\hline 2. & $\begin{array}{l}\text { Taking into account the diversity in the selection of training } \\
\text { methods according to the needs of practical trainees. }\end{array}$ & 3.56 & 1.17 & 2 \\
\hline 3. & $\begin{array}{l}\text { He shall endeavor to innovate and innovate in the methods used } \\
\text { according to the trainee's scientific specialization. }\end{array}$ & 3.33 & 1.24 & 3 \\
\hline 4. & $\begin{array}{l}\text { Provide clear and specific justification when using the training } \\
\text { method. }\end{array}$ & 3.64 & 1.17 & 4 \\
\hline 5. & $\begin{array}{l}\text { aking into account the fairness in the distribution of tasks and } \\
\text { duties. }\end{array}$ & 3.36 & 1.23 & 5 \\
\hline 6. & $\begin{array}{l}\text { Consistency between training time and covering all theoretical } \\
\text { aspects. }\end{array}$ & 3.07 & 1.39 & 6 \\
\hline Total mean Total & Focuses on diversity in assessment methods. & 3.43 & 0.99 & 1.10 \\
\hline 1. & Be careful about continuous evaluation after finishing sessions. & 3.36 & 1.13 & 2 \\
\hline 2. & $\begin{array}{l}\text { Focuses on the effectiveness of the emphasis to achieve the } \\
\text { objectives of the course. }\end{array}$ & 3.12 & 1.01 & 3 \\
\hline 4. & Focuses on the application of what the learner learns. & 2.69 & 1.08 & 4 \\
\hline 5. & $\begin{array}{l}\text { The efficiency method is used to determine the extent to which } \\
\text { the trainees develop their performance as a result of the training. }\end{array}$ & 3.15 & 1.01 & 5 \\
\hline 6. & $\begin{array}{l}\text { The training time shall be taken into account in terms of the } \\
\text { training period, the timing of the training programs and their } \\
\text { compatibility with the training content and the trainer. }\end{array}$ & 3.08 & 1.05 & 6 \\
\hline Total mean & $\begin{array}{l}\text { Total } \\
\text { environment. }\end{array}$ & 3.14 & 0.70 \\
\hline
\end{tabular}




\begin{tabular}{|c|c|c|c|c|}
\hline 2. & $\begin{array}{l}\text { Training seeks to improve training programs and assist } \\
\text { management in making decisions to identify training needs. }\end{array}$ & 3.27 & 0.94 & 2 \\
\hline 3. & $\begin{array}{l}\text { The training seeks to reveal the extent to which training } \\
\text { programs contribute to meeting the needs of the university. }\end{array}$ & 3.36 & 1.04 & 3 \\
\hline 4. & $\begin{array}{l}\text { The training seeks to identify the negative aspects faced by the } \\
\text { university and the college. }\end{array}$ & 3.11 & 1.08 & 4 \\
\hline 5. & $\begin{array}{l}\text { The training contributes to solving differences and problems at } \\
\text { the university. }\end{array}$ & 3.20 & 1.07 & 5 \\
\hline \multicolumn{2}{|c|}{ Total mean Total } & 3.16 & \multicolumn{2}{|l|}{0.73} \\
\hline 1. & $\begin{array}{l}\text { The trainer uses a training method that is appropriate to the } \\
\text { training topic. }\end{array}$ & 2.80 & 1.19 & 1 \\
\hline 2. & $\begin{array}{l}\text { The instructor uses modern work methods resulting from } \\
\text { generalization. }\end{array}$ & 2.84 & 1.33 & 2 \\
\hline 3. & He applies all his knowledge of new information and skills & 2.95 & 1.31 & 3 \\
\hline 4. & The trainee acquires leadership skills at work. & 3.02 & 1.29 & 4 \\
\hline 5. & Trainee courses acquire time management skills. & 3.21 & 1.18 & 5 \\
\hline 6. & $\begin{array}{l}\text { Training in bridging existing training needs and their suitability } \\
\text { facilitates the training environment (materials, location, } \\
\text { methodology and methods used in training). }\end{array}$ & 3.07 & 1.17 & 6 \\
\hline 7. & $\begin{array}{l}\text { Contributes to identifying the negative aspects facing the } \\
\text { training process at the university }\end{array}$ & 3.01 & 1.13 & 7 \\
\hline 8. & $\begin{array}{l}\text { he trainer uses a training method that is appropriate to the } \\
\text { training topic. }\end{array}$ & 3.69 & 0.97 & 8 \\
\hline \multicolumn{2}{|c|}{ Total mean Total } & 3.07 & \multicolumn{2}{|l|}{0.89} \\
\hline
\end{tabular}

Table (3) shows the arithmetical averages, standard deviations and the rank for each of the paragraphs in the fields to which they belong, as follows:

First: the field of training method

Table (4) shows the arithmetical averages, the standard deviations and the rank for each paragraph of the field of training method and the field as a whole. It is noted that the arithmetical averages for the fields of this field ranged from 3.07 to 3.65 and with a medium to large evaluation of the paragraphs. The field as a whole obtained an average of 3.43 and a standard deviation of 0.99 and a high level of evaluation.

(1) and stated: "The trainer uses the training method that matches the objective of the course" with an average of 3.65 and a standard deviation of 1.19 and a high level of evaluation. The researcher attributed this to the attention of the development center and the trainers in particular by using the training methods in their diversity and multiplicity in proportion to all the scientific and literary disciplines, which made the university deserve the top ranking in the international classification and international accreditation.

The second item came in paragraph (4) and stated: "There shall be clear and specific justification when using the training method" with an average of 3.64 and a standard deviation of 1.17 and a high level of evaluation.

Finally, paragraph (6) states that: "Consistency between training time and covering all theoretical aspects shall be considered" with an average of 3.07 and a standard deviation of 1.39 and a medium rating.

Second, the field of training evaluation

It is noted from Table (3) that the mathematical averages on the field of training evaluation ranged between 2.693.47 and the medium to large evaluation level on the paragraphs. The field as a whole obtained an arithmetic mean (3.14) and a standard deviation (0.70) Average rating.

First came paragraph (1), which states: "It focuses on the diversity of assessment methods" with an average of 3.74 and a standard deviation of 1.10 and a high degree of evaluation.

The second item came in paragraph (2), which states: "The continuous evaluation after completion of courses" shall be followed by an average of 3.36 and a standard deviation of 1.13 and a medium grade.

Finally, paragraph (4) states: "It focuses on the application of what the trainee learns" with an average of 2.69 and a standard deviation of 1.08 and a medium rating.

Third, the field of identifying training needs

From Table (4), the mean and standard deviations and the rank for each paragraph of the field of training needs ranged between 2.88-3.36 and the average level of assessment of all the paragraphs. The field as a whole obtained an average of 3.16 and a standard deviation 0.73 ) and at an average rating level.

First, paragraph (3) states: "The training seeks to reveal the extent to which the training programs contribute to meeting the needs of the university" with a mean (3.36), a standard deviation (1.04) and a medium level of evaluation.

Second, paragraph (2) states: "Training seeks to improve training programs and assist management in making 
decisions to identify training needs" with an average of 3.27 and a standard deviation of 0.94 and a medium rating. Finally, paragraph (1) states: "Training needs are derived from the need and reality of the working environment" with a mean (2.88), a standard deviation (1.04) and an intermediate level of assessment.

Fourth area of training content

Table 4 shows the arithmetical averages, the standard deviations and the rank for each paragraph of the training content area and the field as a whole. The mathematical averages for this field ranged between $(2.80-3.69)$ and the average to large level of assessment of the paragraphs. He obtained an average of (3.07) and a standard deviation (0.89) and an average rating level.

First, paragraph (8) states: "It contributes to identifying the negative aspects facing the training process at the university" with an average of (3.69) and a standard deviation (0.97) and a high degree of evaluation.

Second, paragraph (5) states: "The trainee acquires leadership skills at work" with a mean (3.21), a standard deviation (1.18) and an intermediate grade level.

Finally, paragraph (1) states: "Training content is linked to actual training requirements" with an average of 2.80 and a standard deviation of 1.19 and an average grade of assessment

2-Results for answering the second question: Are there statistically significant differences in the level of significance $(0.05=\alpha)$ between the responses of the study sample members of the teaching staff at the University of Science and Technology due to the variables of the study (gender, college, and academic level)?

In order to answer this question, the statistical averages and standard deviations were extracted to the extent of the responses of the sample members on the effectiveness of the training programs in the Center for Accreditation and Quality Assurance at the University of Science and Technology from the point of view of the faculty members according to the variables of study (sex, Below shows the results.

Table (4) The statistical averages and standard deviations of the grades of the sample of the study on the effectiveness of the training programs in the Center for Accreditation and Quality Assurance at the University of Science and Technology from the point of view of faculty members Gender variable, type of college and academic grade

\begin{tabular}{|c|c|c|c|c|c|c|}
\hline Variable & Categories & & & & & \\
\hline \multicolumn{2}{|l|}{ Gender } & $\begin{array}{l}\text { Trainin } \\
\text { Method }\end{array}$ & $\begin{array}{l}\text { Training } \\
\text { Evaluatio }\end{array}$ & $\begin{array}{l}\text { Identification } \\
\text { Training }\end{array}$ & $\begin{array}{l}\text { Training } \\
\text { Content }\end{array}$ & Means \\
\hline & Male & 3.72 & 3.29 & 3.31 & 3.21 & 3.37 \\
\hline & Female & 0.85 & 0.68 & 0.75 & 0.91 & 0.59 \\
\hline \multirow[t]{2}{*}{ College } & $\begin{array}{l}\text { College of Human } \\
\text { Sciences }\end{array}$ & 2.90 & 2.87 & 2.90 & 2.82 & 2.87 \\
\hline & $\begin{array}{l}\text { Scientific and } \\
\text { applied }\end{array}$ & 1.00 & 0.64 & 0.75 & 0.79 & 0.60 \\
\hline \multirow[t]{3}{*}{$\begin{array}{l}\text { Academic } \\
\text { Rank }\end{array}$} & $\begin{array}{l}\text { Assistant } \\
\text { Professor }\end{array}$ & 3.09 & 2.96 & 2.91 & 2.76 & 2.92 \\
\hline & $\begin{array}{l}\text { Associate } \\
\text { Professor }\end{array}$ & 1.16 & 0.70 & 0.82 & 0.83 & 0.70 \\
\hline & Professor & 3.57 & 3.22 & 3.26 & 3.20 & 3.31 \\
\hline
\end{tabular}

The results of the independent study (gender, college and academic level) are shown in Table 4, and to detect the significance of these differences in the arithmetic mean, MANOVA) using the Wilk's Lambda test at the $\alpha=$ 0.05 level. Table (6) builds the results of the Wilkes test for the principle and results of multivariate analysis.

Table (6) Results of the analysis of the variance of the difference between the estimates of the sample members on the areas of effectiveness of training programs at the Center for Accreditation and Quality Assurance at the University of Science and Technology from the point of view of faculty members and the total mark by gender variable, type of university, type of college and educational level

Note from the results of Table (4):

1. There are statistically significant differences at the level of statistical significance $(=0.05)$ between the average estimates of the sample in all fields for the effectiveness of the training programs in the Center for Accreditation and Quality Assurance at the University of Science and Technology from the point of view of faculty members due to the difference in gender variable. For males, the mean values were higher for females than for females, and there were statistically significant differences at the level of statistical significance ( $=0.05$ on the instrument as a whole due to differences in sex variable. The differences were also favoring males. The difference in the nature of males as they are more disciplined and committed to instructions and regulations and laws compared to females because of its nature as it is the responsibility of the responsibilities and duties of life it is necessary to be more committed and reflected commitment to improve the scientific and then the economic and financial, and indicate the difference of both sexes in their perception For the dimensions and effectiveness of training The results of this study differ with the study (shahrouz fariad, 2012), which showed no differences in the 
responses of members of the study sample according to gender variable. . With the study (wang, 2015) 2. There are no statistically significant differences at the level of statistical significance $(=0.05)$ between the average estimates of the sample members on the field of training method and the field of training evaluation for the effectiveness of training programs in the Center for Accreditation and Quality Assurance at the University of Science and Technology from the point of view of faculty members $(=0.05)$ between the average of the sample estimates on the field of determining the training needs and the field of the training content and the tool mark as a whole for the effectiveness of the training programs in the accreditation and quality assurance center at the University of Science and Technology This is due to the fact that the scientific colleges are more in need of different and renewable training programs for the different nature of disciplines as the scientific colleges depend on the many techniques, multiple and developed. Between the period and the other and different compared to the humanities colleges, which need continuous training for how to use and how to benefit from and how to invest, so it is necessary to be more needed for scientific colleges. .

3. There are statistically significant differences at the level of statistical significance $(=0.05)$ between the average estimates of the sample members on the areas of effectiveness of the training programs in the accreditation and quality assurance center at the University of Science and Technology from the point of view of faculty members and the total mark due to the difference of the academic level variable The difference in favor of the academic rank was an assistant professor compared to the academic rank of associate professor and professor, due to the fact that this group needs more than the other academic levels because it is less experienced than other members in terms of rank, The period of time, so need more training and need more academic programs than other ranks. To judge the effectiveness of training programs

\section{Recommendations}

The following research is proposed

- Expand the scope of the work of the training center at the University of Science and Technology to include all scientific and humanities and the need to move away from the limited training in certain areas only.

- Pay attention to the need to evaluate the results of the training courses carried out in the training center and ensure the quality and reliability and work to provide the different colleges evaluation results.

- The need to encourage all colleges to cooperate with the training centers in universities to access training programs that are more useful. The need to focus on the involvement of females in a larger proportion of the numbers and the implementation and design of these programs and activation.

- The training center at the university should be strengthened with specialized cadres of human resources management, which takes into consideration the dimensions of the training process, whose importance and direct relation to training effectiveness have emerged.

- The Center for Development and Quality should offer training courses that focus on renewal as required by the academic level of faculty members through conducting a survey to determine the requirements and needs of faculty members from the specialized training courses and to provide them with them.

\section{References}

Haidar, Essam (2017). Effectiveness of the training courses offered by the Deanship of University Development in improving the performance of employees at Taibah University, Journal of Educational Sciences, 2 (3): 213-216.

(2017). The reality of the application of quality management in the College of Business Administration at King Saud University from the point of view of their teacher. Research published in the Arab Journal for Quality Assurance of Higher Education, 29 (10): 19-30.

- Al-Qahtani, Amal (2017). The effectiveness of proposed training programs in the light of the quality standards in developing the awareness of the university professor in turn in achieving the requirements of academic accreditation. Journal of Arab Education 24 (106): 221-286.

Abu Teebh, Mr. Abdul Mawla (2013). Effectiveness of a proposed program based on e-training in the development of some e-learning skills among faculty members, a paper presented at the Third International Conference on e-Learning Distance Education, Saudi Arabia.

Adegbija, M.V \& Fakomogbon, MA. \& Daramola, F.O. (2012). The New Technologies and the conduct of EExamination : A case study of National open university of Nigeria. British journal of science, 3(1),59-66

Ahmed Eidan, Jassim (2012). Evaluating the credibility of the training programs implemented by measuring its outputs. Anbar University Journal of Economic and Administrative Sciences, 4 (8): 241-260.

Al Serifi, Mohammed (2009). Administrative Training: Trainers and Training Methods

Al-Sakarna, Bilal (2009). Administrative Training, Amman: Dar Wael Publishing and Distribution.

Al-Sudairy, Mohammed Ahmed. (2018). The impact of training programs on the teaching performance of faculty members at King Saud University, an evaluation study. Journal of Arab Education, 19 (78): 9-84

Baldwin,(2008),T.et al.,Developing Managemen skills, McGrew-Hill, New York, 
Directory of faculty members (2018). University of Science and Technology. Retrieved on 2/11/2018 http://www.just.edu.jo/Centers/AcademicDevelopmentCenter/

Gary Dessler. (2003). Human Resource Management, Translator, Translation / Mohamed Sayed Abdel-Motaly, Riyadh, Dar Al-Marikh.

Haidar, Essam (2017). Evaluation of the effectiveness of training in educational institutions - field study on the vocational guidance center at the University of Damascus. Career Guidance Center.

Jamal al-Din, Mohammed al-Morsi (2003). Strategic Management, Egypt: University House.

Jute wang, yung-I line, shi-you Hou, Adata mining approach for training evaluation simuiation-based trainng , Computers \&industial Engineering, Volume 80,February,pages 171-180.

Kubaisi, Amer Khudair (2010). Administrative and Security Training A Contemporary Vision for the 21 st Century, Naif Arab University for Security Sciences, Riyadh

Muhannad, Khazer (2007). Problems of the practical education program at Mu'tah University faced by principals and principals of cooperating schools from their point of view, Journal of Educational Sciences, 34 (2): 20 30 .

Osang, Fancis. (2012).Electronic Examination in Nigeria, Academic staff perspective - case study: National open University of Ngeria. International and EducationTechnology, 2(4),304-307

Ramadi, Ahmed Idan (2012). Evaluating the credibility of the training programs implemented by measuring their outputs. Research published in Anbar Journal of Economic and Administrative Sciences, 4 (3): 241-260.

Sabri, Maher (2002). Arabic Encyclopedia of Education and Educational Technology, Kingdom of Saudi Arabia: Dar Al-Rashed for Publishing and Distribution.

Sharooz Farjad,(2015). the evaluation effectiveness of training courses in University by kikpartick Model (case study of Islamshar University, periodica- social and Behavioral sciences, Volume 46,

Sparks, D. ,2000 -Issues at the table: Teacher Quality and student Achievement Become Bargaining Matters An Interview with Julia koppaich .journal of staff Development spring,vol. 21, no2 .(Issues at the Table: teacher Quality and student Achievement Become Become Bargaining Matter.Htm). 